\title{
AÇÕES QUE LEVARAM AO BOM DESEMPENHO ESCOLAR: O CASO DE UMA ESCOLA PÚBLICA PAULISTA PERIFÉRICA
}

\author{
Célia Maria Lopes MENDES ${ }^{1}$ \\ Célia Maria DAVID ${ }^{2}$
}

RESUMO: O objetivo deste trabalho é analisar os fatores e ações realizadas por uma escola pública paulista que interferiram positivamente nos indicadores de desempenho e de qualidade da educação oferecida na escola e que têm sido determinantes na construção emancipatória da escola, caracterizando os elementos que levam a escola em tela a obter sucesso em seus resultados. A partir desses indicadores é possível produzir um diagnóstico, identificando os problemas, mas também apontar experiências que deram certo, estabelecendo correlações, corrigindo as falhas, mudando as estratégias. Como Supervisora de Ensino dessa unidade escolar, há três anos, percebo que o gestor (Diretor) toma as decisões com base em informações técnicas e pedagógicas a partir dos indicadores educacionais apresentados pela escola. Percebe-se que há uma preocupação constante do gestor (Diretor) e sua equipe em trabalhar a formação em serviço. Por meio de práticas pedagógicas integradoras e coletivas, tem alcançado bons resultados educacionais nas avaliações internas e externas. A gestão participativa tem sido uma constante na construção das práticas emancipadoras da unidade escolar, possibilitando o envolvimento dos diversos segmentos existentes na escola. Percebemos isso claramente em nossas visitas, aos alunos é dada a vez e voz e possibilidades de se desenvolverem em suas potencialidades. A unidade escolar já possui um histórico de se autoavaliar. Fizemos os questionários dentro das cinco dimensões da gestão com a ajuda o gestor da escola (Diretor).

PALAVRAS-CHAVE: Gestão participativa. Trabalho coletivo. Boas práticas de gestão. Formação em serviço. Práticas pedagógicas integradoras. Autoavaliação.

\section{INTRODUÇÃO}

O papel dos gestores da escola em análise tem sido a implementação de ações que resultem na formação global do cidadão, na intervenção cultural, científica e social na comunidade onde a escola está inserida.

As informações da autoavaliação da instituição são sistematizadas e constituem em dados significativos, colocando no chão da escola o debate sobre a necessidade dos gestores, professores, alunos, funcionários e comunidade escolar, pensarem num projeto de trabalho articulado, levando em consideração a realidade da escola e dos alunos que

\footnotetext{
1 Doutoranda em Serviço Social. UNESP - Universidade Estadual Paulista. Faculdade de Ciências Humanas e Sociais - Programa de Pós-Graduação em Serviço Social. Supervisora de Ensino da Rede Estadual de Ensino do Estado de São Paulo e Diretora de Ensino na Região de Franca. Franca - SP Brasil. 14.403-277 - cmlopesmendes@uol.com.br

${ }^{2}$ UNESP - Universidade Estadual Paulista. Faculdade de Ciências Humanas e Sociais - Programa de PósGraduação em Serviço Social. Franca - SP - Brasil. 14.409-160 - cmdavid48@ gmail.com
} 
a ela tem acesso. Ao mesmo tempo em que se reconhece essa dimensão da experiência, destaca-se os seus limites, inclusive, expressos pelos atores que a vivenciam no âmbito escolar.

Nessa escola, a autonomia executora dos gestores e segmentos é presente, mas nota-se que não se consegue ter governabilidade sobre questões da macro política social. Outro desafio que a escola em tela tem enfrentado e tem tido sucesso são os conflitos que acontecem no bojo da sociedade, não resolvidos e que vão parar no ambiente escolar e que a escola se sente na obrigação de tentar solucionar, até porque são conflitos que interferem no ensino-aprendizagem.

Para enfrentar o grande desafio de encaminhar os jovens da escola ao mundo do trabalho, há uma preocupação grande com o trabalho docente, na execução de políticas públicas educacionais, na formação dos alunos, e algumas parcerias têm sido estabelecidas com a sociedade local.

É uma escola que tem grande preocupação com a implementação do sistema de comunicação, via internet, por meio de rede wireless onde há conexão dentro de todas as salas de aula. É oportunizado aos alunos, professores, funcionários e gestores a inclusão no mundo digital, da informatização e da comunicação virtual, onde são publicadas as avaliações dos alunos, comunicação direta do aluno com os seus professores, bem como notícias, trabalhos realizados por alunos e, uma infinidade de informações úteis ao desenvolvimento de todos.

O Gestor (Diretor) e os Professores Coordenadores têm realizado ações voltadas para a configuração de um quadro de pessoal comprometido com um ensino de qualidade, aprimorando as competências e as habilidades individuais de todos os segmentos.

Arroyo (2000), afirma que os docentes estão buscando competências para ajudar em suas práticas, escolhendo temáticas de reflexão, intervindo e criando estilos de debates. Aprendendo a lidar com as pessoas, acompanhando seus processos de formação e descobrindo seus processos de apreensão de saberes e valores, exigindo a reinvenção de práticas, atividades e intervenções, ou seja, estão reinventando o currículo escolar.

Carvalho e Silva (2001) destacam que historicamente, a forma de organização da escola tem sido marcada pela regra do silenciamento, procurando a homogeneização, a docilidade, a submissão, a ordem e a autoridade. Mas notamos que nessa escola os alunos são acolhidos e incentivados a buscar a ampliação do conhecimento, a colaborar 
na construção de um ambiente harmonioso, não há indisciplina, e sim um diálogo franco sempre que surgem os conflitos, estimula-se o comportamento de independência, suas opiniões são solicitadas, evita-se o distanciamento hierárquico.

$\mathrm{O}$ incentivo e estímulo à participação das famílias, bem como dos elementos comunitários ligados diretamente aos alunos, proporcionam maior estabilidade e efetividade nos resultados obtidos. $\mathrm{O}$ aluno se reconhece no sistema por meio da sua efetiva participação nas decisões do colegiado, por isso busca atuar no contexto pedagógico com maior interesse, pois percebe respeitado em sua individualidade. Freire (1992), afirma que a "leitura do mundo precede a leitura da palavra", com isto querendo dizer que a realidade vivida é a base para qualquer construção de conhecimento.

Os docentes dessa escola têm empenhado para que os alunos se interessem pelos estudos, sintam-se motivados a pesquisar novos caminhos em função do estímulo recebido pelos projetos implementados pelo apoio e parceria que recebem dos gestores da escola.

As tecnologias de Informação (TICs), disponibilizadas a todos os segmentos da escola tem sido uma ferramenta útil, proporcionado novos horizontes na prática didática cotidiana dos docentes despertando a necessidade de realizar práticas pedagógicas inovadoras.

O motivo que levou a pesquisadora a estudar essa unidade escolar é que, embora seja uma escola da zona periférica, com vários problemas existentes em seu entorno consegue desenvolver um bom trabalho escolar oferecendo uma educação de qualidade a todos os alunos, conforme mostram a gestão de resultados educacionais.

Justifica-se, portanto o estudo que nos auxiliará a compreendermos como uma escola que se iniciou a quatro anos, situada em zona periférica da cidade de Franca, funcionando em três períodos, manhã, tarde e noite, com aproximadamente 900 alunos matriculados, com todos os problemas existentes em suas adjacências consiga estar entre as cinco primeiras escolas da Diretoria de Ensino, apresentando bons indicadores educacionais de qualidade.

Os indicadores de qualidade tem sido um instrumento importante nessa escola para fazer o monitoramento e o acompanhamento dos resultados apresentados pela escola. 


\section{DESCRIÇÃO DO TRABALHO}

O trabalho buscará analisar os fatores e ações realizadas por uma escola pública paulista que interferiram positivamente nos indicadores de desempenho e de qualidade.

Para aprofundar as questões abordadas anteriormente tomaremos como referencial teórico: Paro (1998), Hernandez (1998), Gardner (1987), Freire (1992), Arroyo (2000), Perrenoud (2000), Hadji (2001), Carvalho e Silva (2001).

Estes autores tratam das questões suscitadas na análise do trabalho desenvolvido pela escola expõem suas ideias e nos ajudam a refletir sobre o cotidiano escolar.

Trabalharemos com a modalidade de pesquisa, estudo de caso, onde foi feita a autoavaliação pelo Diretor e tabulada pela pesquisadora, com a ajuda do gestor da escola sobre os indicadores de qualidade, que fazem parte dos Resultados Educacionais da Instituição.

Foram feitas perguntas a todos os segmentos da escola, por meio de questionários, e cerca de 90 pessoas envolvendo todos os segmentos da unidade escolar.

Temos como hipótese de pesquisa que ao trabalhar com o Plano de autoavaliação na escola, esse contribui para a melhoria dos processos da Gestão Escolar, que por sua vez contribui para a melhoria dos indicadores de qualidade da gestão.

\section{RESULTADOS OBTIDOS}

Os quesitos avaliados por todos os segmentos foram categorizados em: 1Gestão de resultados educacionais, dentro desse quesito, as questões são sobre; a) avaliação do projeto pedagógico, b) rendimento escolar, c) frequência escolar, d) uso de resultados de avaliação, e) satisfação dos alunos, pais, professores e demais funcionários da escola, f) transparência de resultados. 2- Gestão Participativa, dentro dessa dimensão foi avaliada novamente o projeto pedagógico, b) avaliação participativa, c) atuação dos colegiados, d) interação escola-sociedade, e) comunicação e informação, f) organização dos alunos. 3- Gestão Pedagógica avaliou-se: a) proposta curricular contextualizada, b) monitoramento da aprendizagem, c) inovação pedagógica, d) inclusão com equidade, e) planejamento e prática pedagógica, f) organização do espaço e tempo escolares. 4Gestão de Pessoas, os quesitos avaliados foram: a) visão compartilhada, b) desenvolvimento profissional, c) clima organizacional, d) avaliação do desempenho, e) observância de direitos e deveres, f) valorização e reconhecimento. 5- Gestão de serviços e recursos avaliou-se: a) documentação e registros escolares, b) utilização das 
instalações, c) preservação do patrimônio, d) interação escola/comunidade, e) captação de recursos.

A escola realiza bimestralmente, pelo calendário oficial, reunião coletiva (gestores, professores, alunos, funcionários e pais), onde avalia, sistematiza e socializa o alcance dos objetivos e metas propostos pelo Projeto Pedagógico. São realizadas quatro reuniões bimestrais. As reuniões são registradas em atas dos órgãos colegiados, mapas consolidado com os resultados, e em planilhas criadas pela escola.

Nestas ocasiões são tratados assuntos referentes ao rendimento escolar, frequência escolar, uso de dados das avaliações do SARESP, IDEB, ENEM, para diagnosticar pontos de gargalo no trabalho didático-pedagógico realizado, no Ensino Fundamental e Médio, satisfação dos alunos, pais e professores e demais segmentos da escola, levando em conta a transparência dos resultados.

Há uma divulgação de resultados dos trabalhos e atividades dos alunos por meio de exposição aberta à comunidade.

São realizadas, no final do $1^{\circ}$ semestre e $2^{\circ}$ semestres, reuniões com a presença de representantes dos órgãos colegiados, bem como de funcionários para a elaboração dos planejamentos pedagógicos anuais onde todos podem opinar e propor novas rotas e estratégias que se constituíram como marcos norteadores do ensino oferecido pela escola.

A gestão participativa é pedra fundamental do principio gestor adotado pela equipe e se constitui na formação da identidade da gestão dessa escola.

O gestor e professores atendem pessoalmente os pais ou responsáveis pelos alunos, orientando e ouvindo suas opiniões para as melhores formas de condução do processo ensino aprendizagem. Considerando que a participação de pais ainda é baixa em relação aos outros quesitos já avaliados, a escola tem buscado alternativas para fazer com que esse índice de participação aumente.

Por serem compostos por trabalhadores, os colegiados, participam na avaliação do Projeto Pedagógico somente nos horários disponíveis. A unidade escolar tem buscado solucionar esse problema, convocando-os em período contrários ao de trabalho.

Há uma articulação da escola com as famílias por meio de organização de atividades pedagógicas coletivas, integração com órgãos públicos, infraestrutura da escola, encaminhamento dos jovens ao mercado de trabalho, assistência social, projetos culturais, participação em campeonatos, associação do bairro, trabalho de pesquisa de 
alunos com o comercio local, parcerias com Lyons Club e Rotary, interação com outras escolas no bairro.

O principal canal de comunicação são as reuniões ordinárias e extraordinárias. A abertura da escola para os pais frequentarem a escola no horário do recreio e nas reuniões pedagógicas (ATPC), a comunicação via caderno do aluno, comunicação pelas rádios locais tem contribuído para o aumento da comunicação no ambiente escolar.

A escola foi criada em 2004 já no primeiro ano de funcionamento os alunos forma estimulados a montarem o Grêmio Escolar, por meio do processo eletivo oficial que proporcionou o despertar para a cidadania e o protagonismo político, há participação dos alunos.

A proposta curricular é revista anualmente por ocasião do encontro coletivo escolar para análise planejamento do ano letivo. Inicia-se o ano letivo avaliando o ano anterior, estudando proposituras de novas rotas, reorientação dos projetos de acordo com as especificidades de cada área (seus conteúdos, métodos e aplicação e avaliação). A realidade da comunidade escolar e seu entorno é contemplada no conjunto da proposta curricular consoante suas necessidades de intervenção possíveis no âmbito de ação da escola.

Os resultados do processo ensino/aprendizagem são levantados bimestralmente por meio de avaliações realizadas pelos docentes, seus registros são sistematizados tanto no sistema da SEE, como nas fichas individuais dos alunos e analisados em seus aspectos didáticos pedagógicos, à luz da Proposta Pedagógica da escola.

A escola já desenvolveu práticas pedagógicas inovadoras visando atender à diversidade de características pessoais dos alunos. Desde o início de suas atividades a equipe gestora participa de cursos de formação continuada, direcionados ao uso das TICs, no processo pedagógico.

Alguns projetos de inclusão digital são desenvolvidos na escola, com o objetivo de promover a inclusão digital da comunidade escolar: alunos, professores, funcionários e comunidade, durante a semana e nos finais de semana, que muito contribuiu para a aprendizagem de todos.

A escola é dotada de acessibilidade para pessoas com necessidades educacionais especiais. Há diversos projetos desenvolvidos na escola com o objetivo da inclusão.

Percebemos que se faz necessário a maior integração entre as áreas do conhecimento. As práticas utilizadas pelos docentes constituem-se nos momentos de reuniões de ATPC, porém não efetivas. Nota-se que já houve avanços, alguns 
professores já conseguem planejar as aulas de maneira coletiva, sendo que as áreas que melhor se destacam são as de linguagens e códigos, ciências humanas.

O grupo gestor (Diretor, Vice-Diretor, e Professores Coordenadores), têm preocupação constante em disponibilizar os recursos físicos e equipamentos aos docentes para que isto chegue na sala de aula.

Os profissionais da escola, docentes, agentes de organização escolar e de serviços, e gestores são convidados a participarem de reuniões, palestras, cursos e orientações técnicas, tanto dentro como fora da escola.

Considerando a diversidade de competências e habilidades existentes, o Gestor (Diretor) da escola propôs projeto específico para esse fim: "Formação de docente- em ação", nos horários de A.T.P.C.

Durante as reuniões pedagógicas (ATPC), são realizados estudos da legislação pedagógica e funcional do sistema nacional e estadual e do regimento escolar.

A gestão da escola promove atos coletivos com a presença de professores, funcionários, alunos e familiares, sempre que alguém obtém resultados positivos e construtivos da identidade pessoal e coletiva da escola. Vários alunos já foram premiados em Concursos de Redação e Olimpíada de Matemática.

É realizada anualmente uma feira (EPA), Escola de Portas Abertas à comunidade, com a exposição de trabalhos dos alunos. Também são confeccionados diplomas de honra ao mérito aos alunos e professores que se destacam durante o ano.

A secretaria da escola é muito organizada para manutenção de toda a documentação relativa: à vida escolar do aluno, à vida funcional dos professores, à prestação de informações sobre a escola no geral.

A escola dispõe de infraestrutura mínima, mas é utilizada de forma apropriada, no sentido de disponibilizá-las para o uso amplo a serviço do processo ensinoaprendizagem.

A escola trabalha com o projeto Educação Patrimonial com o objetivo de conscientizar os alunos sobre o direito de uso e dever de conservar o patrimônio, enquanto bem público e coletivo.

A escola é aberta aos finais de semana para que as famílias usufruam dos projetos da Escola da Família, a quadra é usada pela comunidade para campeonatos.

A equipe escolar, juntamente com os órgãos colegiados tem realizado diversas promoções para complementar as verbas recebidas da SEE, mormente na compra de equipamentos multimídias utilizadas nas salas de aula, ventiladores, cortinas, tela para 
proteção superior da quadra de esportes. São realizadas parcerias com empresas com intuito de conseguir recursos pedagógicos, para ministrar cursos e que ajudam a encaminhar os alunos ao mercado de trabalho.

A cada início de ano letivo é realizado um balanço de aplicação dos recursos aplicados no ano anterior e o que pode ser aplicado em recursos para o ano seguinte.

Os momentos de reuniões coletivas são aproveitados para prestação de contas de acordo com os princípios da Gestão Pública (moralidade, impessoalidade, publicidade, legalidade), uma vez que as contas da escola têm sido aprovadas pelos órgãos superior do Tribunal de Constas do Estado, FDE e SEE.

\section{CONCLUSÃO}

De acordo com Paro (1998), a escola é um espaço social que celebra a aprendizagem, vive o encanto da construção da emancipação humana, consolida relações, contribui pra a humanidade. E pela gestão democrática se garante uma prática da construção emancipadora da existência das pessoas e da humanidade.

A nossa hipótese de pesquisa de que a autoavaliação contribui com o processo da Gestão Escolar para elevar a qualidade de educação oferecida na escola se confirmou, tendo em vista que a pesquisadora conhece a realidade da escola, tem sido mediadora entre as políticas públicas e o Projeto Político Pedagógico da escola.

A escola pesquisada é pública, situa-se na periferia da cidade de Franca-SP, é composta por aproximadamente, 900 alunos distribuídos em três turnos de funcionamento. Conta com 36 professores, na maioria efetivos, 11 funcionários e 4 gestores.

É vinculadora da Fundação Casa, e do CDP (Centro de Detenção Provisório), contando com mais 10 professores que trabalham na Fundação Casa.

O que chama a atenção de quem entra na unidade escolar é o comprometimento do grupo gestor com a escola.

O grupo gestor ao tomar conhecimento desses resultados apresentados pela Supervisão de Ensino, já traçou como meta elevar esses indicadores por meio de capacitação aos docentes para trabalharem a interdisciplinaridade entre as disciplinas para diminuir o distanciamento existente entre alguns conteúdos e quanto aos colegiados à escola tem procurado fazer as convocações desses segmentos em horários contrários ao de trabalho, geralmente no período noturno. 
Na escola investigada, observamos que a democracia é construída passo a passo em algumas de suas ações diárias. Esse processo democrático acontece em reuniões dos vários segmentos escolares e em distintos momentos: como os encontros informais na sala do diretor e no ambiente dos professores, nas reuniões para discutir a respeito das orientações administrativas que chegam, ou ainda quando refletem especificamente com seus pares a respeito de projetos e trabalhos a serem desenvolvidos, que privilegiam os interesses dos alunos da escola. Percebemos que na maioria das vezes, esses encontros são cuidadosamente planejados e elaborados pelos gestores, no intuito de melhorar a qualidade de ensino oferecido na instituição.

Todos os esforços realizados por essa escola objetivam a aprendizagem dos alunos, em acolher a comunidade e todos os segmentos, em tornar o ambiente escolar em uma comunidade aprendente.

\title{
ACTIONS THAT TOOK THE GOOD SCHOOL PERFORMANCE: THE CASE OF A PUBLIC SCHOOL SÃO PAULO PERIPHERAL
}

\begin{abstract}
$\overline{\text { ABSTRACT: This work aims to analyze actions and factors achieved by a public school }}$ in São Paulo, which interfered positively on the indicators of performance and quality of education offered at the school and have been determinative in the emancipatory construction of the school, featuring the elements that lead the school to succeed in its results. Starting from these indicators, it is possible to produce a diagnosis, identifying problems, but also pointing experiences that worked out, establishing correlations, correcting faults, changing strategies. As an Educational Supervisor of this educational unit, it has been three years that I have realized that the manager (Principal) makes decisions based on information from technical and pedagogical indicators presented by the school. It is noticeable that there is a constant concern from the manager (Principal) and his team about working out the formation. It has achieved good results in educational internal and external evaluations through cooperative and integrative teaching practices. Participatory management has been a constant in the construction of emancipatory practices of the educational unit, enabling the participation of various segments in school. It was clearly visible in our visits, students are given the time and voice and possibilities to develop their potential. An educational unit has a history of self-evaluation and we made up questionnaires within the five dimensions of management with school manager's help (Principal).
\end{abstract}

KEYWORDS: Participative management. Collaborative work. Good management practices. In-service training. Integrative teaching practices. Self-evaluation. 


\section{REFERÊNCIAS}

ARROYO, M. G. Ofício de mestre: imagens e auto-imagens. Petrópolis: Vozes, 2000.

CARVALHO, M. C. S.; SILVA, A. C. B. Progestão: como construir e desenvolver os princípios de convivência democrática na escola? Brasília: CONSED, 2001. (Módulo V).

FREIRE, P. Pedagogia da esperança: um reencontro com a pedagogia do oprimido. Rio de Janeiro: Paz e Terra, 1992.

GARDNER, H. Estrutura da mente: a teoria das inteligências múltiplas. Porto Alegre: Artes Médicas, 1987.

HADJI, C. Avaliação demistificada. Porto Alegre: Artmed, 2001.

HERNANDES, F. Transgressão e mudança na educação: os projetos de trabalho. Porto Alegre: Artmed, 1998.

PARO, V. Gestão democrática da escola pública. São Paulo: Ática, 1998.

PERRENOUD, P. Dez novas competências para ensinar. Porto Alegre: Artmed, 2000 .

\section{BIBLIOGRAFIA CONSULTADA}

ALARCÃO, I. Do olhar supervisor ao olhar da supervisão. In: RANGEL, M. (Org.). Supervisão pedagógica: princípios e práticas. 8.ed. São Paulo: Papirus, 2008. p.11-36.

BELLONI, I.; FERNANDES, M. E. A. Progestão: como desenvolver a avaliação institucional da escola? Brasília: CONSED, 2001. (Módulo IX).

BRASIL. Lei n. 9.394, de 20 de dezembro de 1996. Estabelece as diretrizes e bases da educação nacional. Diário Oficial da União, Brasília, 21 dez. 1996.

DOURADO, L. F.; DUARTE, M. R. T. Progestão: como promover, articular e envolver a ação das pessoas no processo de gestão escolar? Brasília: CONSED, 2001. (Módulo II).

FREITAS, K. S.; SOUZA, J. V. de S. Progestão: como articular a gestão pedagógica da escola com as políticas públicas da educação para a melhoria do desempenho escolar? Brasília: CONSED, 2009. Módulo X.

PENIN, S. T. S.; VIEIRA, S. L. Progestão: como articular a função social da escola com as especificidades e as demandas da comunidade? Brasília: CONSED, 2001. (Módulo I).

SÃO PAULO (Estado). Secretaria da Educação. Gestão do Currículo na escola: caderno do gestor. São Paulo, 2009. v.1. 
Secretaria da Educação. Gestão do currículo na escola: caderno do gestor. São Paulo, 2008. v.2 e 3.

SOUSA, J. V.; MARÇAL, J. C. Progestão: como promover a construção coletiva do projeto pedagógico da escola? Brasília: CONSED, 2001. (Módulo III).

TRIGO, J. R.; COSTA, J. A. Liderança nas organizações educativas: direção por valores. Ensaio: Avaliação e Políticas Públicas em Educação, Rio de Janeiro, v.16, n.61, p.561-582, 2008. 